\title{
FLIPPED OUT IN THE BLENDED CLASSROOM, THE GOOD, THE BAD AND THE UGLY: WHEN ACADEMICS BECOME STUDENTS
}

\author{
C. L. van den Berg \\ Department of Information Systems \\ University of the Western Cape \\ Cape Town, South Africa \\ e-mail: cvandenberg@uwc.ac.za
}

\section{B. Verster}

Cape Peninsula University of Technology

Department of Town and Regional Planning

Cape Town, South Africa

e-mail: versterb@cput.ac.za

\section{K.S. Collett}

\author{
Education Studies \\ University of the Western Cape \\ Cape Town, South Africa \\ e-mail: kcollett@uwc.ac.za
}

\section{ABSTRACT}

This article explores the well-being of three academics from different higher education institutions and disciplines, as they engage in professional academic development (PAD) courses using technology. A collaborative autoethnographic approach is applied to reflect on our professional development experience. The higher education landscape is shifting to a cloud-based ICT infrastructure, opening up multiple educational opportunities in teaching and learning. Lecturers in higher education institutions (HEls) are required to use a range of new technological tools and applications and engage in new learning methodologies. This is modelled in professional academic development courses, which integrate technology and digital tools into the teaching and learning process.

Participant perspectives on PAD within a blended learning environment are examined through the lenses of an ethic of care and authentic learning to uncover social justice pedagogy. Using a diffractive approach in a collaborative autoethnographic study, the possibilities, tensions and contradictions of using technology to enhance pedagogy are explored. Findings point to the importance of an Ethic of Care and authentic learning, in order to enhance a social justice pedagogy in PAD.

Keywords: Professional Academic Development, authentic learning, blended learning, ethic of care, social justice pedagogy 


\section{INTRODUCTION AND CONTEXT}

Pressures in higher education are mounting as academics are subjected to higher performance targets in scholarly output, professionalisation of teaching and learning and increased community engagement. Simultaneously resources to enhance staff and student support are decreasing as student numbers increase. In the South Africa unequal resourcing and support in HEIs place further demands (Bozalek, Ng'ambi and Gachago 2013; Jaffer, Ng'ambi and Czerniewicz 2007).

The demands on academics are exacerbated by the speed of change brought on by digital technology. Furthermore, academics need to be skilled in aligning pedagogy and technology to benefit student learning (Laurillard 2013). The rapid emergence of technological innovations enables an increase in blended learning that combines traditional face-to-face instruction with computer mediated or online instruction (Bonk and Graham 2012). Academics are faced with a wide variety of technological tools and applications with which to engage with students and colleagues. Increasingly they are forced to test and implement new learning methodologies (Adams Becker et al. 2017). Academics furthermore need to be competent enough to know when, how and where to implement educational technology and how to facilitate the transition (Englund, Olofsson and Price 2017).

The student Fallist movement through the \#RhodesMustFall and \#FeesMustFall campaigns at HEI between 2014 and 2016, drew attention to the need for transformation in HEIs. Academics and HEIs were challenged to address issues of equity and social justice in their curriculum content, pedagogy and culture (Booysen 2016; Naicker 2016).

Within this context Fisher and Tronto (1990) and Tronto's (2013) work on a political ethic of care has been found to provide a meaningful framework to inform social justice pedagogy in both student and academic professional development (Leibowitz et al. 2015; Council of Higher Education 2017). In this article, we explore how a social justice perspective in a blended learning environment promotes access to resources and equal opportunities for success.

Professional academic development programmes such as those run by the Cape Higher Education Consortium (CHEC) have supported educators in HEIs to engage critically on their curriculum content, pedagogy and enhance teaching and learning through the use of a range of technologies (Council of Higher Education 2017). While a number of studies have focused on the need to enhance pedagogy and learning using technology (Ng'Ambi 2013; Sharpe, Beetham and De Freitas 2010; Bates 2015), few studies have been done by academics themselves on the value of technology assisted blended learning models of professional academic development programmes. 
Using a collaborative autoethnographic approach, we apply a diffractive reading to our experience (Barad 2007, 2014). Our particular focus is on being and learning through a blended learning environment that required engagement with a range of information technologies. We apply the lenses of social justice pedagogy (Moje 2007); an ethic of care (Tronto 2010; 2013) and authentic learning (Herrington 2000, 2006) to diffractively read our "insights through one another" (Barad 2007, 71). The collaborative exploration of our data reveals new insights into PAD showing up the good, the bad and the ugly.

This article aims to make a contribution to this field by bringing attention to participant experiences of a social justice and ethics of care perspective within authentic, blended learning programmes. We argue that the design of PAD courses within a blended learning environment need to be informed by an ethic of care and principles of authentic learning in order to promote a social justice pedagogy. We conclude with perspectives on how courses using a blended learning approach in HEI's can enhance or constrain social justice pedagogy. Thus drawing attention to teaching and learning design principles that can mitigate against participants becoming "flipped out" in a blended learning environment.

\section{LITERATURE AND THEORIES INFORMING THE STUDY}

\section{Social justice pedagogy}

According to Moje (2007), social justice pedagogy needs to offer opportunities for access to knowledge and learning, as well as the ability to challenge, question and reconstruct knowledge. She argues that it "should offer possibilities for transformation not only for the learner, but also of the social and political context within which learning and other social action takes place" Moje $(2007,4)$. This approach holds resonance with the concept of participatory parity (Ngoasheng and Gachago 2017) as it addresses issues of economic maldistribution, cultural misrecognition and political misrepresentation as they influence the teaching and learning context.

Leibowitz and Bozalek (2016) argue that technology can play a role in supporting social justice pedagogy as it offers students choices in learning and it has the potential to accommodate a wider group of students.

Leibowitz and Bozalek (2016) assert that working towards social justice in higher education requires attention to the needs of students, academics, administrators and other roleplayers. Within this context they highlight the complexity in addressing social justice needs as needs can be conflicting requiring processes of negotiation and dialogue.

In the ethics of care framework, Fisher and Tronto (1990) and Tronto (2013) provide a 
useful framework to inform social justice pedagogy. In essence, its phases and associated moral dimensions affirm what Moje (2007) refers to as a culturally responsive pedagogy.

\section{A political ethic of care}

Joan Tronto contends that social justice discussions do not work well unless they are linked to an ethic of care and calls for the need to put back the human face in HEIs (Tronto 2016).

Tronto's work has gained prominence in informing the pedagogical practices of academics in higher education both nationally and internationally (Collett, Van den Berg, Verster and Bozalek 2018). Tronto's work is informed by a relational ontology that is holistic and interdependent and systemic in nature. It highlights nuances in the moral dimension of interactions between people, the environment and society at large. It sheds light on issues of power, authority and caring in collaborative engagements. Bozalek et al. (2014) and Collett et al. (2018) have used it as a framework to illuminate the personal, public political dimension of care within professional academic development programmes.

Care is defined by Tronto and Fisher (cited in Tronto 2013, 22) as including "everything that we do to maintain, continue, and repair our world so that we can live in it as well as possible". Their notion of care is holistic and systemic as it includes a focus on individuals within society and in relation to the broader environment. This conception of care enables an understanding of higher education pedagogical practice that takes into account both the micro dynamics at the interface between lecturers and students, as well as the broader societal and global forces that influence teaching and learning in higher education (Zembylas, Bozalek and Shefer 2014).

Tronto (2013), identify five phases of care with corresponding moral elements of care. Each phase of care builds upon the next. Phases on care include caring about; caring for; caregiving giving; care receiving and caring with.

\section{Caring-about associated with attentiveness}

Caring about with its corresponding moral element of attentiveness is the first phase of care identified by Tronto (2013). This phase is characterised by "someone or some group noticing unmet caring needs" (ibid. 1990, 40, cited in Tronto 2013, 22). Attentiveness requires "a suspension of one's self-interest" and a capacity to observe the perspective of the one in need (Tronto 2013, 34). It further requires a focus on the specific needs of each individual and the “uniqueness of each person's position” (Bozalek et al. 2014, 4). 


\section{Caring-for associated with responsibility}

Caring for is the second phase of care, associated with the moral element of responsibility. It requires a person to respond to the needs of others, or as Tronto and Fisher put it "someone or some group has to take responsibility to make certain that these needs are met" (cited in Tronto 2013, 22). Responsibility includes a willingness to "take on the burden of meeting those needs" (Tronto 2013,34) and is "embedded in a set of implicit cultural practices rather than a set of formal rules ..." (Tronto 1993, cited in Bozalek et al. 2014, 452).

\section{Care-giving associated with competence}

Care-giving associated with the moral element of competence. This phase "requires that the actual caregiving work be done" (Tronto 2013, 22). It requires one "to be competent to care" and is "not simply a technical issue, but a moral one" (Tronto 2013, 35). Tronto (1993) qualifies competence as including care-giving that addresses accessing materials and resources such as time and skill.

\section{Care-receiving as associated with responsiveness}

Care-receiving is associated with the moral quality of responsiveness. Tronto (2013) asserts that "the person cared for need not be the one who completes the process of responding, but some response is necessary" (Tronto 2013, 35).

\section{Caring-with associated with trust and solidarity}

Caring-with associated with the moral qualities of trust and solidarity. Tronto (2013) identifies this phase with democratic practice, she explains, "caring needs and the ways in which they are met need to be consistent with democratic commitments to justice, equality, and freedom for all" (Tronto 2013, 22).

Within teaching, learning and assessment practices the above phases of care and their associated moral qualities can be applied, in order to review the extent to which the needs of students and academics are engaged with to support social justice pedagogy.

\section{Authentic learning}

The framework for authentic learning has proven to be beneficial in the design of technologybased learning environments and aid the elements of a blended learning approach (Oliver, Herrington and Reeves 2006).

Authentic learning is based on the theoretical foundation of situated learning (Herrington 2006). Learning designs to promote situated learning are often applied to professional and 
vocational education, where there is a clear incentive to develop certain skills and competencies within a profession (Beetham and Sharpe 2013). In 1997, Herrington expanded on the work by Brown, Collins and Duguid (1989), Lave and Wenger (1991) and McLellan (1991) and developed a model for authentic learning that could successfully be applied to educational practice.

The principles of authentic learning as outlined in Herrington, Reeves and Oliver (2014) are described as:

- Provide authentic contexts that reflect the way the knowledge will be used in real life. Reallife problem solving is not an individual task but involves collaboration and a shared consequence.

- Provide authentic task/s to enable learners to demonstrate their skills and competencies. These need to have real-world relevance, be ill defined, continue over an extended period and be integrated across subject areas.

- Provide access to expert performances and the modelling of processes by allowing learners' access to experts, collaboration with other learners and expert facilitation.

- Provide multiple roles and perspectives to move away from linear methods of instruction and s expose learners to different perspectives.

- Support the collaborative construction of knowledge tasks in which group work is required to complete tasks and the appropriate assessment is in place to emphasise whole-group achievement.

- Promote reflection to enable abstractions to be formed during the completion of tasks and afterwards.

- Promote articulation to enable tacit knowledge to be made explicit. Learners need to discuss their learnings as their understanding grows within their collaborative groups and via presentations during class.

- Provide coaching and scaffolding at critical times to support learning.

- Provide for integrated assessment of learning within the tasks to provide the opportunity to demonstrate acquired knowledge. Assignments need to allow enough time for students to collaborate with others.

Thus authentic learning provides a model for the structuring of a learning environment where the focus is on authenticity and learning for real-world issues. The principles informing an authentic learning approach highlight issues of social construction of learning in real world 
context with carefully constructed opportunities for scaffolded learning to meet participant need. There is a strong congruence between these principles and a social justice approach to curriculum and pedagogy informed by an ethic of care.

We used these frames to interrogate the design and execution of blended learning as it pertained to PAD and in turn the design of our own learning environments.

\section{RESEARCH DESIGN}

\section{Context and participants}

The authors of this article were participants of higher education staff development courses offered by the Cape Higher Education Consortium. They represent two different HEIs and lecture in diverse disciplines. They are seasoned academics that shared a common interest in enhancing collaborative learning through technology in the design of their learning processes.

The CHEC short course "Designing Learning with Technologies" provided training and enabled the participants to actively engage with different types of technology and take what they learned to their own teaching practice. Knowledge and practice in the use of technology in the design of learning, enabled participants to apply technology tools to accomplish a variety of different tasks. The second course attended was "Research on teaching and learning: preparing for your proposal" and the aim was to assist academics to improve their teaching and learning practice.

\section{Methodology}

We applied a collaborative autoethnography methodology in the collection and analysis of our data. Autoethnography (AE) demands rigorous, multi-layered levels of researcher reflexivity because the researcher and the researched are the same (Short, Turner and Grant 2013). It is an iterative process of reflexion and reflexivity where fractions of one experience link to fractions of another experience "it is in principle infinite, open, and unlimited in every direction" (Deleuze, Guattari and Massumi 1987, 525).

Collaborative Autoethnography (CAE) combines the "unique strengths of self-reflexivity associated with autobiography, cultural interpretation associated with ethnography, and multisubjectivity associated with collaboration" (Chang, Ngunjiri and Hernandez 2013, 17).

We drew on a diffractive analysis of the data to enable a more detailed exploration of the intra-actions between different viewpoints, and from different perspectives. This gave rise to what Bozalek and Zembylas (2017) refer to as new creative visions.

Data was generated through reflection on our practice, reflection on each other's practices 
and reflection via participatory learning activities (see Figure 1), recorded conversations and interactive interviews.

Data that held a common resonance and ignited our interest and passion on the course was selected drawing on the concept of data that "glows" (MacLure 2013, 661).

Reflection happened iteratively between individual reflections of practice, collective reflection and sharing of our key learning to make meaning and identify themes. We realised that reflection was not giving us the deeper meanings we wanted as the sameness and not the differences kept shining through.

A diffractive reading of the data, drawing on the work of Donna Haraway (1992) and Karen Barad (2007) enabled new creative visions and insights to emerge. Diffraction opens up new knowledge via a process of reading disciplines and texts through one another. A diffractive methodology does not put one theory against another or engage in critiquing the ideas of the one and eulogising the other, but reads the one through the other (Collett et al. 2018).

As argued by Bozalek and Zembylas $(2017,119)$, diffraction can be regarded as an "ethical and socially just practice" because different viewpoints and stances are built on to form new knowledge. Tronto's five phases of care, the existence of authentic learning and tenets of social justice pedagogy were diffractively read through each other in order to explore our experiences in face-to-face and online interaction. Collective analysis of our data with these diffractive readings made it possible for new insights to surface through the process of engagement.

\section{CRITICALLY DIALOGIC MEANING-MAKING AND ANALYSIS}

We analysed our individual and collective experiences by reviewing the elements that we found to be the good (possibilities), the bad (tensions) and the ugly (contradictions) within the blended learning environment. Chang et al. $(2013,43)$ refer to this as concurrent collaboration where researchers work independent from each other on the same task of data generation and collection but collaborate during the data analysing stage. As argued by Chang et al. $(2013,28)$ in this collaborative process of meaning-making, participants must be "willing to be vulnerable and open with co-researchers in order to enable the deeper analysis and interrogation that enriches the final product".

We had a series of deepened conversations about blended learning and how this related to our PAD and what we now mirror in our own practices. The initial layer was to find meaning and engage with our data to find the "data that glowed" (MacLure 2013, 661). This enabled a deepened engagement to explore the good, the bad and the ugly.

The complexity of the collaborative meaning-making process required us to meet weekly and to further schedule off campus, overnight writing retreats. Through the application of CAE 
in writing, reflection and then collaborative diffraction, we deepened our understanding as academics that became students.

\section{The good}

\section{Apprenticeship}

We engaged with one another via a face-to-face and an online community of practice. Through this modelling of a blended learning environment, we were able to emulate the experience in our own teaching, and the design of future courses. Lave and Wenger (1991) refer to this engagement in a community of practice as fostering an apprenticeship in good teaching and learning.

“... other group members agreed on the impact of the modelling of blended learning in this course and how it provides us with scaffolding in thinking about the development of our own courses out of what we have experienced." (Author, reflection week 3).

"This multimodal connectivity exposed me to both a depth of learning, as well as breadth of learning at the same time. New literature and questions raised during the learning, reflection and feedback process helped me to deepen my engagement with concepts related to my research focus." (Author, final reflective notes).

\section{Accelerated learning}

Engagement in on-line and face-to-face collaboration deepened and accelerated our learning both individually and at a collective level. This accelerated learning pace is visible in our comments and participatory learning activities (PLA) in Figure 1.

"My research timeline reflects the discomfort and growth that being in this blended learning course ushered in, and the learning trajectory it facilitated." (Author, reflective notes, PLA drawings).

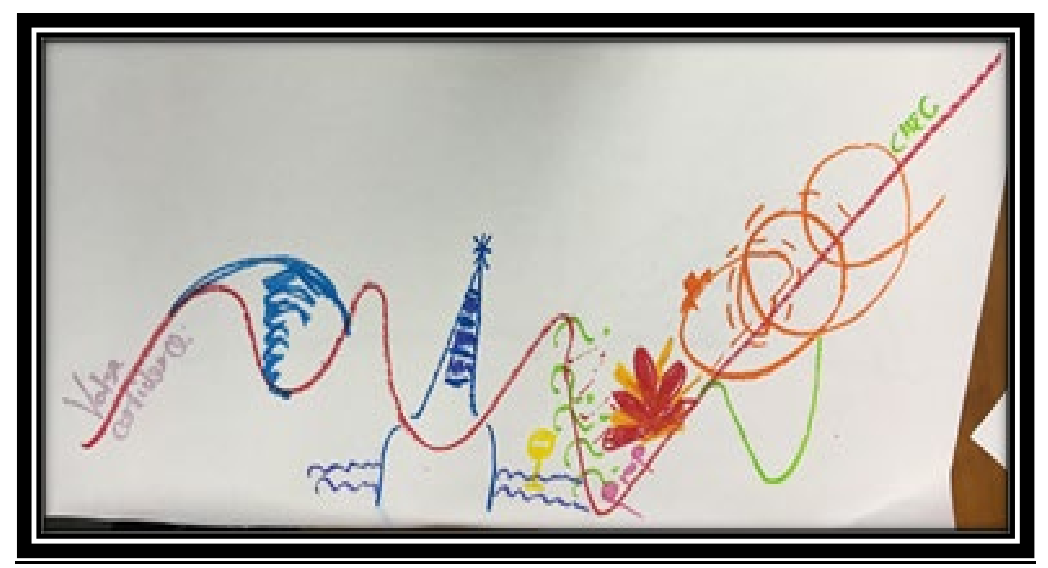



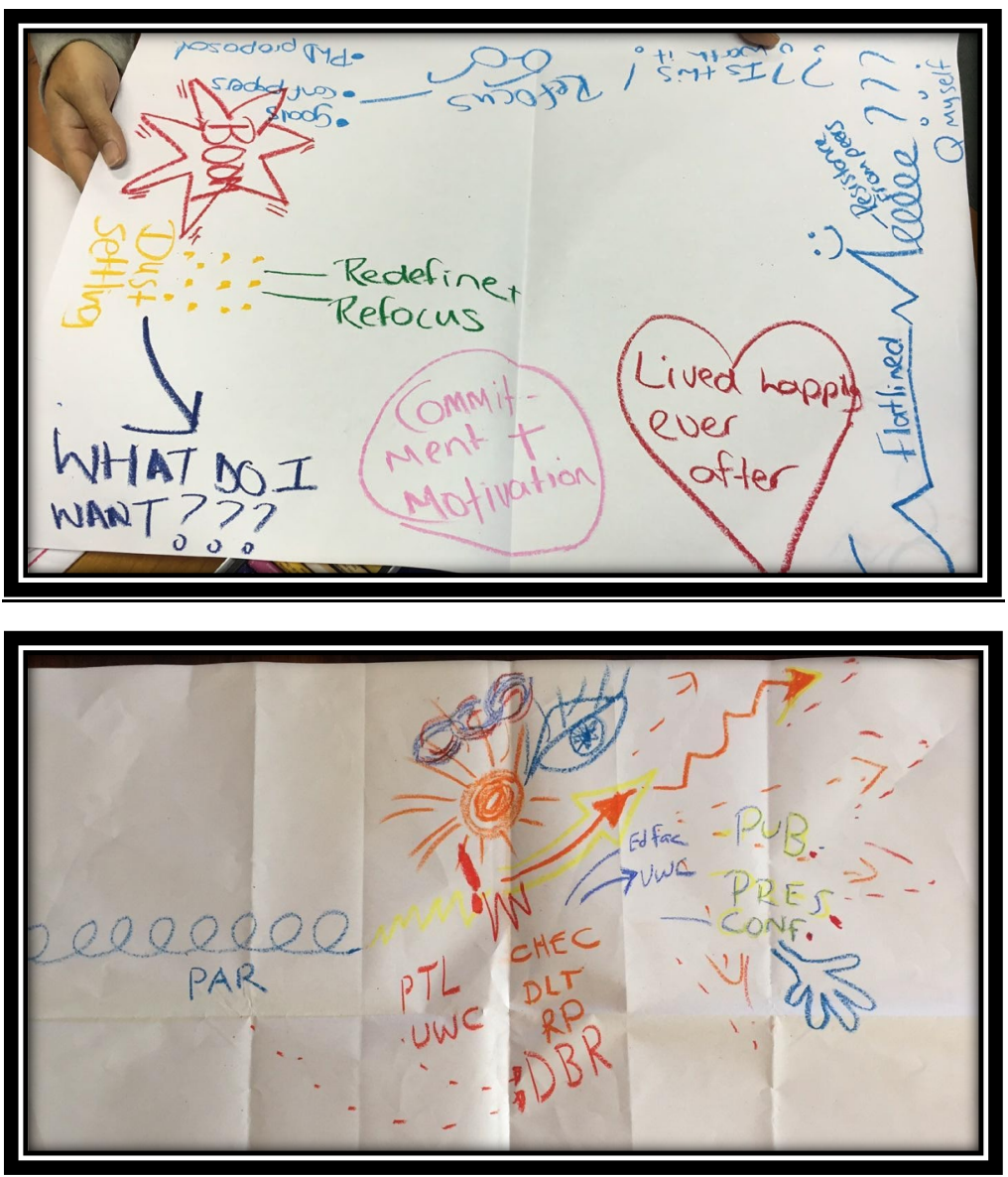

Figure 1: PLA drawings

\section{Collaborative community of practice}

We collaborated from the start of the first course and shared our stories and observations, which was a crucial element to create an authentic learning experience. The elements of ethics of care were present in the course facilitation and this allowed us to form a strong bond of trust and solidarity with one another.

"Displaying an ethic of care in the facilitation of the process enabled the community to form deeper insights because there was a combined responsiveness and responsibility towards each other that formed into a trust relationship." (Authors, diffractive intra-action).

Establishing trust and solidarity was a critical factor supporting deep learning. It prevented us from merely affirming the views of other participants. Rather, it supported us to uncover deeper meaning and being critical friends that asked the difficult questions. The community gave as a safe place to experiment, make mistakes and engage freely in a blended learning environment.

"The way in which the course is set out provides the affordances of being able to engage with one another in a safe place of learning and support." (Author, reflection week 4). 
"I had a need within my practice to understand how collaboration works, real collaboration and how technology can enable it. I found a group of people with the same objective and it helped me to hold onto the group and to learn from one another and find out what the others were doing. My need was to learn from the experiences of other academics. We were learning together but each individual brought different strengths." (Authors, diffractive intra-action).

Groups were formed around a common need establishing a community of practice.

"We had a common purpose and this proved to be an essential component in the design of the course. Having an interest in a common purpose brought us together in a community of practice where there was a similar focus and where we were able to learn from one another." (Authors, diffractive intra-action).

\section{The power of reflection}

We experienced the structured reflective exercises as one of the fundamental building blocks of developing a strong, collaborative learning environment. Through technology participants were expected to read and comment on each other's reflections. This provided opportunities for attentiveness to the needs of others as we had insight into group member's personal struggles and achievements. We were able to directly respond to both the emotional and cognitive needs in a timely and supportive way. This built empathy and social cohesion to facilitate an ethic of care in our group.

"The power of internalizing triggers (learning and reflection opportunities) is priceless." (Author, reflection week 1).

This short reflection elicited a supportive response from a critical friend, who commented:

"I really like your tenacity. I wonder if this can be traced back to some ... bloodline. I have it, and it comes in handy." (Critical friend, week 4).

\section{The value of feedback}

"Although an assessment requirements provided the external structure that placed an external pressure on us to write and comment regularly, we noted that the quality and type of feedback we provided to each other was influenced by a level of trust and communal camaraderie in the group. A common research focus and need to widen and share our knowledge also facilitated the deepening of feedback and the sharing of resources." (Author, reflection week 4).

We built group cohesion and interpersonal relations through a focus on a common task and (passion), as well as a desire to support and help each other. This assisted us to feel "at liberty" or "free" to comment on the written work of peers through structured feedback. A strong sense of shared responsibility was cultivated by expecting course participants to give and share feedback. 
The centrality of feedback to the learning process trickled down to our teaching and learning practice as demonstrated by the following quote:

"Providing students with feedback has been shown to be a key factor in learner/student achievement particularly when numerous cycles of formative and summative feedback are encourage." (Author, reflection week 3).

A growing group identity and solidarity built around a systematic process of collaborative reflection on our own and each other's practice, as elaborated on below.

"There needs to be an identity that develops within the group around a common need that enables feedback to take place much easier within the group. Allow conversations to take place to reflect and have critical friends giving feedback. There was a shared responsibility in the structure due to the assessment criteria but through that intra-action with one another, a relationship was formed. The way that we responded to one another's needs helped to build the trust and the community of practice to carriyed one another in the process." (Authors, diffractive intra-action).

\section{Innovation}

As educators, we are forced to explore new innovations in our teaching and learning. Cobo (2013) stresses the disparity between what is being taught in formal education versus what is required by an innovative society such as multi-disciplinary thinking. This is echoed by Wagner (2012), who claims that education is neither adding value nor teaching the skills that matter most in the marketplace. The link between technologies and collaborative learning ignited energy for learning and sharing in a supportive community with a common purpose, passion and intention to produce new knowledge (Wenger 1998). This gave us the confidence to test out our ideas with one another and the broader group. We went on to implement innovations using technology to enhance a collaborative, blended learning environment in our own modules.

"I have incorporated a number of other technologies into supporting both my planning and delivery of my teaching. For example through Google Docs I aim to get feedback on my assessment activities and course planning and how they incorporate Critical Literacies; I have also decided to encourage my students to work on a Group Assignment using Google Docs and to experiment a range of technologies in doing class presentations." (Author, reflection week 4).

"I have been fortunate to build connections with a special community of colleagues who share a common practice outside of my Faculty and also beyond UWC. I hope to keep connected via our online and face-to-face links as we take forward our research and publication journeys towards improving our teaching and learning. Soon I hope to say - WE HAVE A LIFT OFF!!!” (Author, final reflections). 


\section{The bad}

\section{Access to technology and connectivity}

We reviewed our reflections to find those aspects that inhibited our learning and caused discomfort or tension within the blended learning environment. Coming from different disciplines, the cognitive dissonance experienced in our engagement with new technologies was more overt for some of us.

"Not having a laptop or smartphone feels like not having part of my brain to help me learn. Peers with technology access are getting ahead while I stay behind playing catch up." (Author, reflection week 1).

"I had to wait for our IT department for assistance to set up my office computer to be able to link online. I don't think my students will have this level of support." (Author, reflection, week 2).

"I lost Internet connectivity at home and became extremely frustrated by the online environment and guilty about not being able to provide feedback to peers. I suppose students often have this problem with limited connectivity and limited access to online facilities after hours." (Author, reflection week 3 ).

"With technology it was assumed that students will have access to technology and attention was not given to different people's technological needs and level of skills. This highlighted pointers to towards our own pedagogy, particularly in environments where you have students with different levels of skills and access to technology. We needed technology to do the assessment tasks and $24 / 7$ access. There was an assumption that everyone was on-board and had unlimited access. We were doing this in a language that we all understood. We wondered what would happen if you cannot articulate yourself in an online environment and if you are not confident to express yourself." (Authors, diffractive intra-action)

\section{Scaffolding to enable reflection and feedback}

We all experienced the need for a greater level of scaffolding to enable us to know how to reflect and what reflective models can be applied. We also felt that we needed scaffolding on how to give and receive feedback in a blended learning environment.

"I did not feel that I was in a position to reflect on anything that would be meaningful to the other respondents. Without any scaffolding to help one to know how to reflect was intimidating as you are making yourself public and committing yourself to write down your thoughts. The permanency of that and not knowing how it will be received and not having scaffolding in place such as a rubric to know what you can draw on to form your reflections. The reflection template was not explained and did not provide the guidance needed. It was hard to reflect on our own practice and to know what the expectations were without clear instructions. You did not know what experience other people had and if you pass a comment how that will be perceived." (Authors, diffractive intra-action).

"There was a level of unconsciousness from facilitators about our level of comfort in giving and receiving feedback. What made it difficult to give feedback was you had to feel competent about your own ability to give feedback on research as an expert. Also the giving of feedback to peers was uncomfortable as I did not know how direct or critical one could be. We needed scaffolding 
in how to give and receive feedback. In the CHEC course on research, providing feedback was even harder because you had to review someone else's literature review, research design etc." (Authors, diffractive intra-action).

\section{Push for content as opposed to process}

An aspect that we felt needed to be reviewed was the balance between time for content input and group processes of reflection and sharing of learning. What was bad for us was limited time to share learnings happening in small groups with the bigger group during face-to-face sessions.

"Often more time is needed to ensure that something is being bedded down before you push on with the programme. We needed more time to respond to each other and for a report to develop. For care to be received a space to respond is necessary and more time for dialogue and engagement is needed. We did not engage much with other groups in the class due to the focus on content input rather than process." (Authors, diffractive intra-action).

\section{The ugly}

Areas of our data that glowed "red hot" with emotions of frustration or anger are what we termed ugly. A key issue here was the fast pacing of tasks intensified within the blended learning environment. We experienced an imbalance between the amount of time given to engage with complex tasks and the time given to complete tasks such as literature reviews or exploring the affordances of different technologies.

\section{Pacing of assessment tasks and activities using technology (cognitive load)}

We found the pacing of tasks and subsequent assessments to be a crucial element in the design of a blended learning environment. From our experience, more time was needed to engage with the literature, reflect on our experience and share our findings. We needed more time to process information and to absorb complex content.

\footnotetext{
"In our group I also felt that I wanted more time to be able to follow up on some of the feedback that they had given me in the written form. I felt we needed a gap to consolidate and share key questions or ideas with group members - before we went on to the next section we were jumping through hoops too fast." (Author, reflective notes week 4).

"Although I found this process of learning exciting, it also created a great deal of stress as I tried to cope with the multiple levels of learning and learning relationships that were happening over a short period of time." (Author, final reflective notes).
}

We questioned and debated the pace of the courses and the impact thereof on our learning and how to ensure sensitivity and support for a range of barriers to learning.

We concurred that the pace did not allow us to be attentive and responsive at times to our own 
needs, the needs of each other and our families. It was a challenge to balance our time between full-time jobs, family commitments and doing a course of this nature to complete certain tasks adequately. We felt that this may be particularly true when one engages with technologies and processes that are new and aspects of work that require deep levels of engagement with a range of bodies of literature.

"This experience made me more sensitive to what I needed to think about when designing courses for my students with blended learning approach using technology to facilitate learning. With hindsight I would say to improve the learning process on this course in the future, I propose giving at least a two week slot for participants to be able to access, engage with and begin to write up their review of the literature." (Author, reflection end of course).

"The speed at which things are happening and the way that the course was scaffolded was problematic. There is just no time to breathe and catch up if you struggled one of the weeks. Giving up becomes a real consideration in these circumstance." (Author, final reflection).

"The ugly has to do with the pacing. The pacing of activities needed to be more carefully considered - so that flipped out feelings did not translate into a consideration of dropping out. Getting into stages where you become paralysed and want to leave the course because you feel so consciously incompetent that you cannot manage to continue." (Authors, diffractive intra-action).

\section{Blurring boundaries}

The blended learning environment provided us with new ways to connect and collaborate. The threat is that one starts to blur your boundaries between what is virtual and what is real, what is public and private and what is work and what is leisure (Morgan 2013).

\footnotetext{
"Now the expectation was that learning happens 24/7 with the doors of learning and culture staying open WIDE. Sleep and my own well-being (and that of my two children) had to take a back seat as my hunger to learn and keep up took over." (Author, reflection end course 1).

"The level of emotional and intellectual energy or labour that went into me relating to peers by sharing my writing, resources and ideas with them, and learning from them and with them in the e-learning environment was intense." (Author, reflection end course 1).

"In our group and personal reflections we focused on this and concurred that to make this manageable for ourselves we had to set some boundaries and only provide online feedback to one or two peers. Very few of us were able to find the time to engage with other groups." (Author, reflection end course 1).
}

\section{FINDINGS AND RECOMMENDATIONS}

Attention to the integration of the principles of authentic learning and ethics of care promoted the empowerment and agency of participants. Collaboration of participants in the development of innovations, in a community of practice that shared a common interest, were key to promoting participant engagement with curriculum content and delivery. Group trust and solidarity were built through sharing reflections and assisting each other to complete tasks. The 
role of the facilitator in providing attentive and responsive feedback and support was critical in enabling participants to build confidence and agency in directing learning. These factors strongly promoted a social justice pedagogy of affect.

The use of a blended learning environment with its accelerated pace enabled deepened learning for both individuals and groups. Whilst the use of technology boosted connectivity, it also raised points of tension where individuals felt disempowered by the accelerated pace of learning or limitations in their own skills sets to utilise and access technology.

Although a focus on an ethics of care sought to pay attention to individual needs, the design of the curriculum as a whole required a greater sensitivity towards the timing and pacing of what participants were expected to master. This calls for a greater level of scaffolding and differentiated teaching to address a range of learning, language and technological needs in blended learning environments.

In addressing social justice needs, a process of negotiation and dialogue is needed. We argue in favour of such a space of dialogue to identify differentiated needs and subsequent pacing of activities to foreground the time and depth needed for engagement in groups. This requires a better balance between process and content input, particularly in a blended learning environment where there has been accelerated, deep learning between contact sessions.

The key principles that need to be addressed include group formation, facilitating a caring environment, timing and pacing to scaffold learning and deepened learning.

\section{Group Formation}

- Establish common areas of interest before course commencement to inform group formation.

- Attend to group formation to include people with a range of skills and technological abilities.

- Develop group norms for working in collaborative communities of practice in face-to-face and online environments.

- Include reflection on practice and engagement and feedback on these reflections by group members.

\section{Facilitating a caring environment}

- Imbue the facilitation with all the elements of an ethics of care (Tronto 1993; 2013).

- Mirror the pedagogy and process in the face-to-face and online environments. 


\section{Timing and pacing to scaffold learning}

- Identify technology expertise and needs to plan for the scaffolding of different abilities.

- Incorporate elements of authentic learning in the course design (Herrington, Reeves and Oliver 2010).

- Review the pacing and timing of assessment tasks that require complex skills such as engagement with new technology or a literature review.

- Scaffold standards and expectations through practical examples the assessment of tasks.

- Make provision for flexible timelines for complex tasks to support differentiated learning needs and technological challenges.

\section{Deepened learning}

- Provide scaffolding for reflection through the use of different reflective models.

- Include marks for reflection on writing, as well as the eliciting of feedback through written comments to peers and the facilitator.

- Develop student competence in providing feedback through identifying what feedback students find most useful and what literature recommends.

- Provide opportunities for dialogue and engagement with feedback in relation to assessment outcomes.

- Enhance opportunities for small groups and the larger group to surface new learning and insights, and reflect on learning.

- Ensure a healthy balance between process and content, and err on the side of process within a blended learning environment.

\section{CONCLUSION}

This article applied a collaborative autoethnographic approach between three academics to explore blended learning within professional academic development. Their individual and collective perspectives were explored through the lenses of an ethic of care and authentic learning to uncover social justice pedagogy. A diffractive approach was applied in this exploration to review the good (possibilities), the bad (tensions) and the ugly (contradictions) within a blended learning environment.

The good identified aspects such as apprenticeship, accelerated learning, a collaborative community of practice, the power of reflection, the value of feedback and the ability to innovate. In the collective review of the bad, tensions in terms of access to technology and connectivity, scaffolding to enable reflection and feedback and the push for content as opposed 
to process were experienced. The pacing of assessment tasks and activities using technology as well as the blurring of boundaries were classified as the ugly within a blended learning environment.

Whilst a blended learning environment enabled deepened learning, it also invoked tensions where individuals felt conscious of their own incompetence. This highlighted the importance of a greater sensitivity towards the timing and pacing of activities. In addressing this and allowing for social justice needs, the necessity of negotiation and dialogue became apparent. The key principles to address in blended learning were identified as group formation, the facilitation of a caring environment, timing and pacing to scaffold learning and a focus on deepened learning.

Findings point to the importance of an integrated approach in the design and facilitation of blended learning courses through the application of authentic learning and ethics of care. These factors strongly promoted a social justice pedagogy of affect. Thus drawing attention to teaching and learning design principles that can mitigate against participants becoming "flipped out" in a blended learning environment.

\section{Disclosure statement}

No potential conflict of interest was reported by the authors.

\section{REFERENCE LIST}

Adams Becker, Samantha, Michele Cummins, Annie Davis, Alex Freeman, C. Glesinger Hall and Vidya Ananthanarayanan. 2017. NMC Horizon Report: Higher Education edition. The New Media Consortium.

Colett, Karen, Carolien van den Berg, Belinda Verster and Vivienne Bozalek. 2018. Incubating a Slow pedagogy in professional academic development: An ethics of care perspective. South African Journal of Higher Education 32(6): 117-136.

Barad, Karen. 2007. Meeting the universe halfway: Quantum physics and the entanglement of matter and meaning. Duke university Press.

Barad, Karen. 2014. Diffracting diffraction: Cutting together-apart. Parallax 20(3): 168-187.

Bates, Anthony William. 2015. Teaching in the digital age. Vancouver BC: Tony Bates Associates Ltd.

Beetham, Helen and Rhona Sharpe. (Eds.). 2013. Rethinking pedagogy for a digital age: Designing for 21 st century learning. Routledge.

Bonk, Curtis J. and Charles R. Graham. 2012. The handbook of blended learning: Global perspectives, local designs. John Wiley \& Sons.

Booysen, Susan. (Ed.). 2016. Fees must fall: Student revolt, decolonisation and governance in South Africa. Wits University Press.

Bozalek, Vivienne, Dick Ng'ambi and Daniella Gachago. 2013. Transforming teaching with emerging technologies: Implications for higher education institutions. South African Journal of Higher Education: Special Issue: Forum of the Southern African Association of Institutional Research 27(2): 419-436. 
Bozalek, Vivienne, Wendy McMillan, Delia E. Marshall, Melvyn November, Andre Daniels and Toni Sylvester. 2014. Analysing the professional development of teaching and learning from a political ethics of care perspective. Teaching in Higher Education 19(5): 447-458.

Bozalek, Vivienne and Michalinos Zembylas. 2017. Diffraction or reflection? Sketching the contours of two methodologies in educational research. International Journal of Qualitative Studies in Education 30(2): 111-127.

Brown, John Seely, Allan Collins and Paul Duguid. 1989. Situated cognition and the culture of learning. Educational Researcher 18(1): 32-42.

Chang, Heewon, Faith Wambura Ngunjiri and Kathy-Ann Hernandez. 2013. Collaborative autoethnography. California: Left Coast Press.

Cobo, Christobal. 2013. Skills for innovation: Envisioning an education that prepares for the changing world. Curriculum Journal 24(1): 67-85.

Council of Higher Education. 2017. Learning to teach in higher education in South Africa. Pretoria: CHE.

Deleuze, Gilles, Félix Guattari and Brian Massumi. 1987. Capitalism and schizophrenia Vol. 2: A thousand plateaus. Translated by Brian Massumi. Minneapolis: University of Minnesota Press.

Englund, Claire, Anders D. Olofsson and Linda Price. 2017. Teaching with technology in higher education: Understanding conceptual change and development in practice. Higher Education Research \& Development 36(1): 73-87.

Fisher, Berenice and Joan Tronto. 1990. Toward a feminist theory of caring. In Circles of care: Work and identity in women's lives, ed. E. Abel and M. Nelson, 35-62. SUNY Press, Albany, NY.

Haraway, Donna. 1992. The promises of monsters. A regenerative politics for inappropriate/d others. In Cultural Studies, ed. Lawrence Grossberg, Cary Nelson and Paula A. Treichler, 295-337. New York: Routledge.

Herrington, Jan. 2000. An instructional design framework for authentic learning environments. Educational Technology Research and Development 48(3): 23-48.

Herrington, Jan. 2006. Authentic e-learning in higher education: Design principles for authentic learning environments and tasks. World Conference on E-Learning in Corporate, Government, Healthcare, and Higher Education, ed. T. Reeves and S. Yamashita, 3164-3173. Chesapeake, VA: AACE.

Herrington, Jan, Thomas C. Reeves and Ron Oliver. 2010. A guide to authentic e-learning. British Journal of Educational Technology 42: 167-184.

Herrington, Jan, Thomas C. Reeves and Ron Oliver. 2014. Authentic learning environments. In Handbook of research on educational communications and technology, 401-412. New York: Springer.

Jaffer, Shaheeda, Dick Ng'ambi and Laura Czerniewicz. 2007. The role of ICTs in higher education in South Africa: One strategy for addressing teaching and learning challenges. International Journal of Education and Development using ICT 3(4).

Laurillard, Diana. 2013. Teaching as a design science: Building pedagogical patterns for learning and technology. Routledge.

Lave, Jean and Etienne Wenger. 1991. Situated learning: Legitimate peripheral participation. Cambridge University Press.

Leibowitz, Brenda and Vivienne Bozalek. 2016. The scholarship of teaching and learning from a social justice perspective. Teaching in Higher Education 21(2): 109-122.

Leibowitz, Brenda, Vivienne Bozalek, Susan van Schalkwyk and Christine Winberg. 2015. Institutional context matters: The professional development of academics as teachers in South African higher education. Teaching in Higher Education 69(2): 315-330.

MacLure, Maggie. 2013. Researching without representation? Language and materiality in postqualitative methodology. International Journal of Qualitative Studies in Education 26(6): 658667. 
McLellan, Hilary. 1991. Virtual environments and situated learning. Multimedia Review 2(3): 30-37.

Moje, Elizabeth Birr. 2007. Chapter 1: Developing socially just subject-matter instruction: A review of the literature on disciplinary literacy teaching. Review of Research in Education 31(1): 1-44.

Morgan, John. 2013. The impact of technology on teaching and learning. Universitas 21. http://www.formatex.info/ict/book/513-517.pdf

Naicker, Camalita. 2016. From Marikana to \#feesmustfall: The Praxis of popular politics in South Africa. Urbanisation 1(1) (May): 53-61.

Ng'Ambi, Dick. 2013. Effective and ineffective uses of emerging technologies: Towards a transformative pedagogical model. British Journal of Educational Technology 44(4): 652-661.

Ngoasheng, Asanda and Daniela Gachago. 2017. Dreaming up a new grid: Two lecturers' reflections on challenging traditional notions of identity and privilege in a South African classroom. Education as Change 21(2): 187-207.

Oliver, Ron, Jan Herrington and Thomas Reeves. 2006. Creating authentic learning environments through blended learning approaches. In The handbook of blended learning: Global perspectives, local designs, ed. C. J. Bonk and C. R. Graham, 502-515. San Francisco: Pfeiffer.

Sharpe, Rhona, Helen Beetham and Sara De Freitas. 2010. Rethinking learning for a digital age: How learners are shaping their own experiences. Routledge.

Short, Nigel P., Lydia Turner and Alec Grant. 2013. Contemporary British autoethnography. Sense Publishers.

Tronto, Joan C. 1993. Moral boundaries: A political argument for an ethic of care. Psychology Press.

Tronto, Joan C. 2010. Creating caring institutions: Politics, plurality, and purpose. Ethics and Social Welfare 4(2): 158-171.

Tronto, Joan C. 2013. Caring democracy: Markets, equality, and justice. NYU Press.

Tronto, Joan. 2016. Keynote. ICED and Heltasa Conference, Cape Town, November.

Wagner, Tony. 2012. Creating innovators: The making of young people who will change the world. New York: Scribner.

Wenger, Etienne. 1998. Communities of practice: Learning, meaning, and identity. Cambridge University Press.

Zembylas, Michalinos, Vivienne Bozalek and Tammy Shefer. 2014. Tronto's notion of privileged irresponsibility and the reconceptualisation of care: Implications for critical pedagogies of emotion in higher education. Gender and Education 26(3): 200-214. 